\title{
Integrating Hot and Cool Intelligences: Thinking Broadly about Broad Abilities
}

\author{
W. Joel Schneider ${ }^{1, *}$, John D. Mayer ${ }^{2}$ and Daniel A. Newman ${ }^{3}$ \\ 1 Department of Psychology, Illinois State University, Normal, IL 61790, USA \\ 2 Department of Psychology, University of New Hampshire at Durham, Durham, NH 03824, USA; \\ jack.mayer@unh.edu \\ 3 Department of Psychology and School of Labor \& Industrial Relations, University of Illinois at \\ Urbana-Champaign, Champaign, IL 61820, USA; d5n@uiuc.edu \\ * Correspondence: wjschne@ilstu.edu; Tel.: +1-309-438-8410
}

Academic Editor: Robert J. Sternberg

Received: 8 July 2015; Accepted: 22 January 2016; Published: 30 January 2016

\begin{abstract}
Although results from factor-analytic studies of the broad, second-stratum abilities of human intelligence have been fairly consistent for decades, the list of broad abilities is far from complete, much less understood. We propose criteria by which the list of broad abilities could be amended and envision alternatives for how our understanding of the hot intelligences (abilities involving emotionally-salient information) and cool intelligences (abilities involving perceptual processing and logical reasoning) might be integrated into a coherent theoretical framework.
\end{abstract}

Keywords: emotional intelligence; personal intelligence; hot intelligences; broad abilities; Cattell-Horn-Carroll Theory of Cognitive Abilities

E. O. Wilson [1] argued that scientists should work toward achieving a consilient integration of theories across diverse domains of human knowledge. In this article, we work on an admittedly smaller integration-but one that, someday might contribute to the whole: an integration of the concepts of cool and hot intelligences. Over the 20th century, most commonly studied intelligences concerned the cool, impersonal features of information. People generally agree on the meanings of the words bicycle, rain, house, and wealth; where there is any question, they defer to the authoritative judgments rendered in dictionaries, encyclopedias and similar reference works. Another cool intelligence concerns memory: One can remember a phone number, a grocery list, or the most popular movies of 2015-these are generally impersonal recollections (although some may be of considerable importance at a given moment in time).

By comparison, a subset of intelligences-hot intelligences-concern abilities involving the processing of highly charged and personally significant information such as emotions, personality, and social relations [2]. Thus far, theory development about hot intelligences has proceeded mostly alongside and somewhat apart from that of the cool intelligences [3]. Although there are advantages to developing detailed, narrowly focused theories, it seems to us productive to conceptually compare the hot intelligences with the cool intelligences and speculate how they might be integrated into a coherent common framework.

\section{How Is the Existence of a Broad Ability Established?}

We will begin to examine some of the issues involved in integrating cool and hot intelligences with an examination of how intelligences are related to one another more generally. As we consider how these types of intelligence might be related, we are mindful that our primary statistical tools in cognitive ability research-regression, factor analysis, and structural equation modeling-are like old-school Lego bricks. With a little ingenuity, they can be used to approximate almost any kind of 
structure, but their nature biases the builder toward rectilinear designs. If Horn and Noll ([4], p. 84) are correct that a mature theory of cognitive abilities is likely to resemble the "rounded and irregular structures of mother nature", we should begin to think about intelligence in ways that go beyond the tidy hierarchical structures that characterize traditional factor-analytic models (see Figure 1).

To appreciate the complexities and the opportunities involved, we will discuss current conceptions of intelligence in the factor-analytic tradition-spending some time on how they evolved historically so as to give a flavor of the historical learning process in the field-and then turn to more contemporary concerns.

Box 1: Is there a consensus definition of intelligence?

Before we can discuss the integration of intelligence theories, it is helpful to describe what is meant by intelligence first. We should be clear that we are not offering a binding definition of intelligence. Although there is an impulse to retrofit terms from everyday language with scientific precision, efforts to do so are usually unsatisfying. Mike Brown, who discovered several "dwarf planets" and many other large objects in our solar system beyond Pluto, explained why he does not take seriously the International Astronomical Union's official definition of the term planet that excluded Pluto ([5], p. 242):

In the entire field of astronomy, there is no word other than planet that has a precise, lawyerly definition, in which certain criteria are specifically enumerated. Why does planet have such a definition but star, galaxy, and giant molecular cloud do not? Because in astronomy, as in most sciences, scientists work by concepts rather than by definitions. The concept of a star is clear; a star is a collection of gas with fusion reactions in the interior giving off energy. A galaxy is a large, bound collection of stars. A giant molecular cloud is a giant cloud of molecules. The concept of a planet-in the eight-planet solar system-is equally simple to state. A planet is a one of a small number of bodies that dominate a planetary system. That is a concept, not a definition. How would you write that down in a precise definition?

I wouldn't. Once you write down a definition with lawyerly precision, you get the lawyers involved in deciding whether or not your objects are planets. Astronomers work in concepts. We rarely call in the attorneys for adjudication.

There is probably no argument more stale than that there is something fishy about the concept of intelligence because no two psychologists can agree on its definition. If you ever find yourself losing an argument, you can usually fight to a draw by doggedly insisting at each turn that your opponent define his or her terms to everyone's satisfaction. Intelligence research has been proceeding quite nicely without a consensus definition. However, if a conceptual description of intelligence is needed, a task force commissioned by the American Psychological Association provides a useful starting point ([6], p. 77):

Individuals differ from one another in their ability to understand complex ideas, to adapt effectively to the environment, to learn from experience, to engage in various forms of reasoning, to overcome obstacles by taking thought. [...] Concepts of "intelligence" are attempts to clarify and organize this complex set of phenomena. [...] Scientific research rarely begins with fully agreed definitions, though it may eventually lead to them.

Similarly, we avoid premature precision in our discussion of the contrasts between hot vs. cool intelligences or broad vs. narrow abilities. These are flexible concepts that have fuzzy boundaries. 


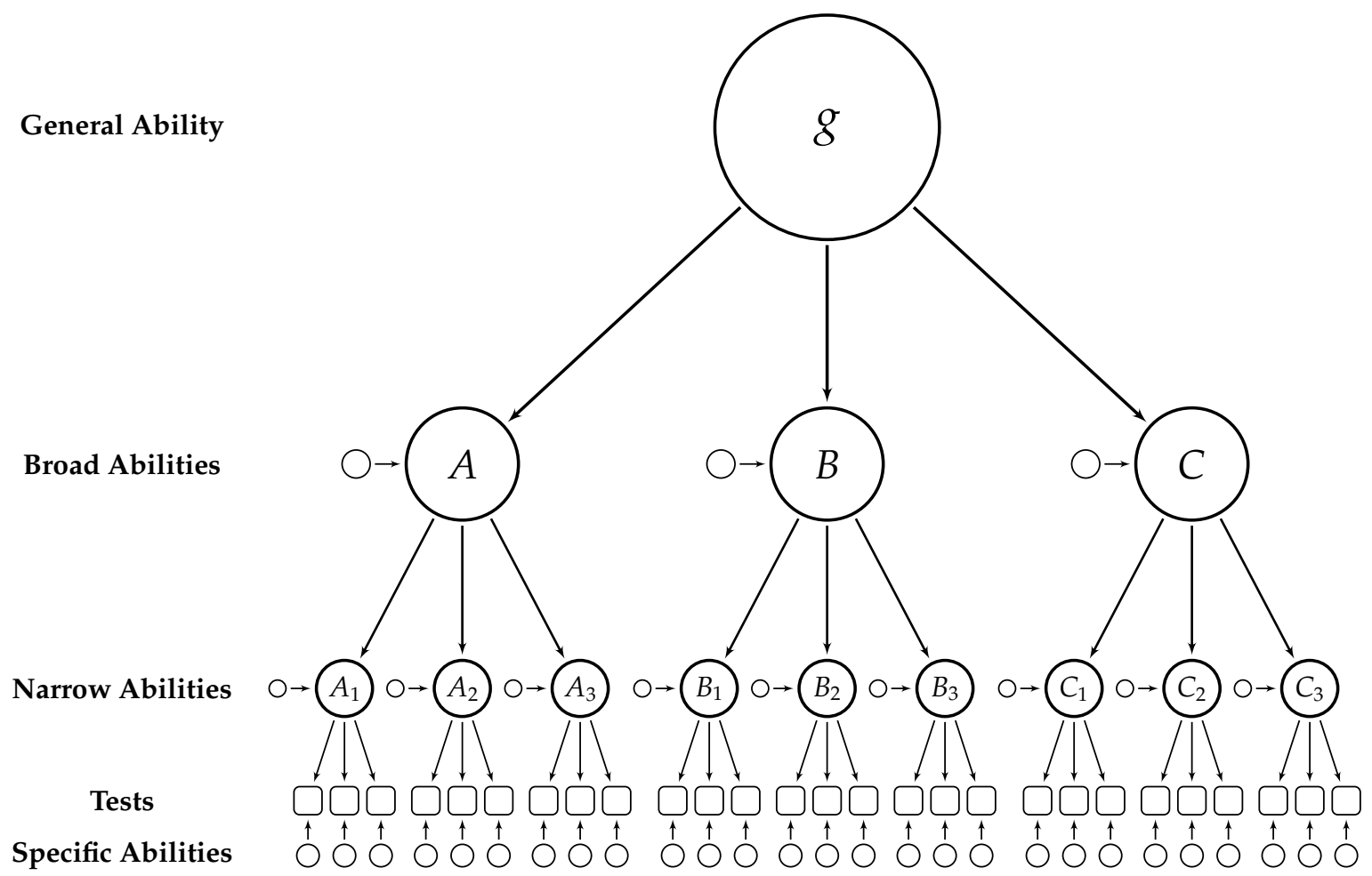

Figure 1. A tidy hierarchical structure.

\subsection{The First Psychometric Model of Intelligence}

Spearman's Two-Factor Theory of Intelligence [7] is arguably the first scientific theory of intelligence in that it explained empirical data better than at least two competing models, and it produced falsifiable hypotheses (that were, in fact, falsified). The theory stated that there is a general factor that is a partial influence on all aspects of intelligence and that there is an indeterminate number of specific abilities that operate under very narrow circumstances. Spearman ([8], p. 5) contrasted his theory with two extreme positions on the structure of intelligence: the anarchic view, in which abilities have no structure and vary at random within individuals, and the monarchic view, in which intelligence consists of a single ability. Both hypotheses failed right from the start; there are many abilities, and their correlations have discernible patterns [7]. Between monarchy and anarchy, there is not a simple continuum, but a vast multidimensional space of possibilities, most of which will never be dreamed of, much less tested. Had Spearman's model been correct, cognitive ability researchers would have been spared the difficult and ongoing task of discerning the complex structure of intelligence.

Spearman's original theory attempted to explain individual differences in intelligence without appealing to the existence of group factors, which are broad abilities that influence sets of related but clearly distinct (i.e., narrow) cognitive abilities. For example, visual-spatial ability consists of many narrow abilities such as visual gestalt perception, visual memory, the ability to imagine how an object would look if it were rotated, and so forth [9]. Spearman's original theory predicts that the correlations among these narrow abilities are entirely explained by the general factor.

Spearman's original theory seemed promising at first, but it did not take long for researchers and theorists to find reasons to doubt the existence of the general factor $(g)$ and to then find positive evidence for the existence of group factors [10-14]. Spearman was able to explain away some of the earliest disconfirming evidence because the distinction between a broad and a narrow ability (i.e., group factors and specific abilities in Spearman's terms) is not always clear. However, by 1927, it was clear even to Spearman that the general factor could not entirely explain the residual correlations between many clearly different abilities ([8], pp. 222-241). Spearman referred to the broad verbal factor as his "hierarchy breaker" because its residual correlations were particularly strong ([15], p. 39). 


\subsection{Early Broad Ability Models}

Spearman eventually modified his theory to accommodate broad factors of intelligence but still argued strongly that $g$ was probably the most important aspect of intelligence [16]. It is telling that after over a century of factor-analytic work on the structure of cognitive abilities, it is still possible for eminent scholars to disagree passionately about whether $g$ represents a mere statistical regularity or an important theoretical entity $(c f .[17,18])$. Clearly, the available evidence is not yet definitively persuasive in either direction.

Using new multivariate factor analytic techniques of his own invention, Thurstone $[19,20]$ attempted to find the fundamental building blocks of cognitive abilities. His Primary Mental Abilities model [21] was an early attempt to identify unitary cognitive abilities that are primary in the same sense that primary colors are primary. Over time, factor-analytic research by Vernon [22], Guilford [23], French and Ekstrom [24,25], Cattell [15], Horn [26], and many others made it clear that Thurstone's primary abilities were not really primary at all; each could be split into ever narrower abilities. In a massive reanalysis of all the world's factor-analytic evidence available up to around 1990, Carroll [9] was able to isolate about 10 broad abilities and 70 narrow abilities, but it is almost certain that there are many more.

\subsection{A Taxonomy of Cool Intelligences}

Although the construct labels often shift, factor-analytic studies have yielded a fairly consistent set of findings since the 1930s about broad abilities within the cool intelligence domain [9,27]. It is not hard to see the resemblance between Thurstone's primary abilities and the increasingly elaborated constructs from more recent psychometric theories [4,28]. Although psychometric theories under active development [29-33] may differ greatly in emphasis, they contradict each other on only a handful of important issues (e.g., the nature of the general factor of intelligence) and are otherwise quite compatible with each other [28,34-37]. We will frame our discussion in terms of the Cattell-Horn-Carroll Theory of Cognitive Abilities (CHC Theory) [27,33,38-40] as a representative psychometric theory of the cool intelligences. It was chosen in part because it is widely accepted $[41,42]$ and has been influential in the development of nearly all recently developed clinical measures of intelligence [43]. More importantly, it is well suited for discussions of theoretical integration because it is proposed as a common framework into which new findings can be incorporated, provided that certain thresholds of evidence are met. In fact, all cognitive ability researchers have a standing invitation to help extend the theory ([39], p. 100).

CHC Theory is primarily an integration of the Horn-Cattell Theory of Fluid and Crystallized Intelligence [4] and Carroll's Three-Stratum Theory of Intelligence [9], two highly similar theories from the factor-analytic tradition in intelligence research. Although CHC Theory is often described as a comprehensive taxonomy of abilities, it is not just a decontextualized list of constructs. In the words of Carroll ([9], p. 68), "To construct a theory of intelligence is to construct a theory of cognition." With each refinement, CHC Theory is evolving away from a simple, unrealistically tidy hierarchical model like Figure 1 and toward a more nuanced account of human intelligence, with constructs that interact dynamically with each other $[39,40,44,45]$.

With over 70 narrow abilities and 16 broad abilities, CHC Theory is complex enough that there are many ways its various features can be depicted $[28,37,39,45]$. In Figure 2, CHC Theory's complexity is reduced by grouping the broad abilities into even broader conceptual categories. Similar to Carroll's [9] model, each grouping has at least one level ability (AKA power abilities) and at least one speed factor associated with it. The motor and perceptual processing abilities—what Cattell ([15], pp. 365-366) called provincial powers - are hypothesized to exist because each has corresponding primary and association regions of the cortex where basic and higher-order processing of motor and sensory codes occurs. Evidence for distinct visual-spatial and auditory processing abilities is more abundant and convincing than for the other hypothesized perceptual factors [39]. 
MOTOR

Abilities
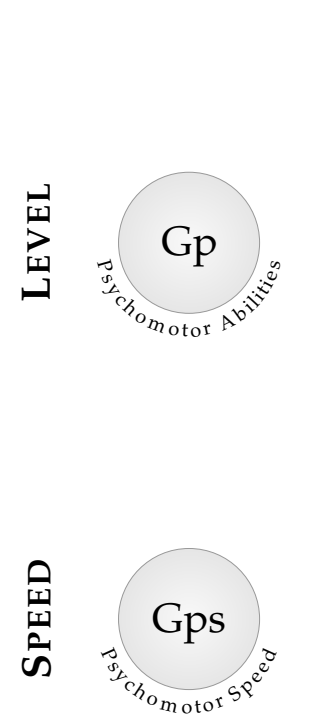
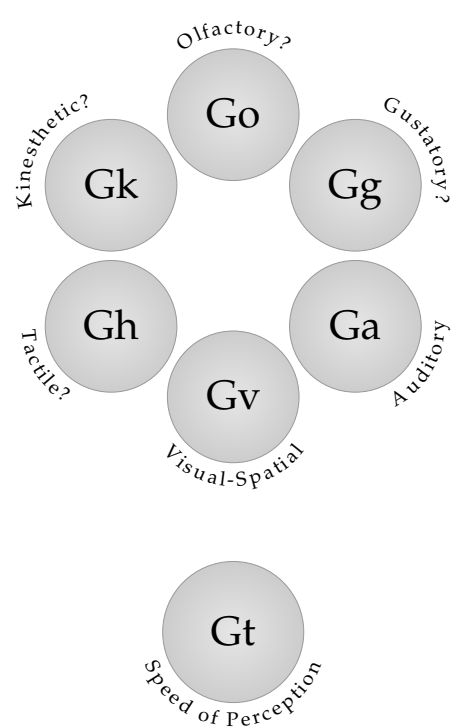

\section{CONTROLLED \\ AtTEnTion}

Perceptual
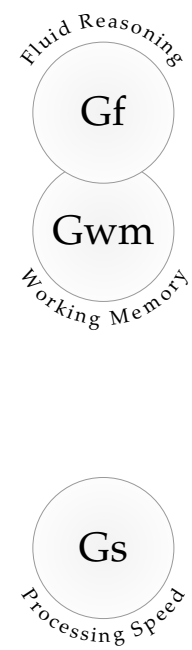

ACQuired

KNOWLEDGE

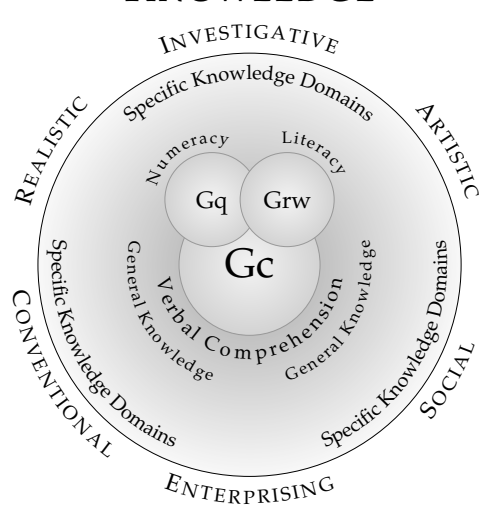

Long-Term Storage \& Retrieval

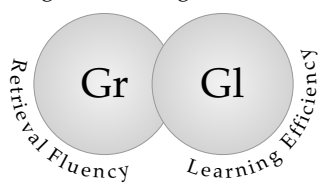

Figure 2. Conceptual Groupings of Broad Abilities in Cattell-Horn-Carroll (CHC) Theory.

Fluid reasoning refers to a domain-general relation-perceiving and problem-solving mechanism that is supported by several domain-general capacities of attention and memory as well as the various domain-specific perceptual processing capacities. That is, if one can hold one's attentional focus on a wide array of information in working memory (whether it be external sensory information shaped by perceptual processing structures or internal knowledge structures retrieved from long-term memory [46]), one is better able to discern useful patterns within this information [26]. The three abilities grouped under controlled attention (fluid reasoning, working memory capacity, and processing speed) are what Horn $[4,26]$ classified as vulnerable abilities in part because they decline most with age, are easily damaged by injury and disease, and are even vulnerable to disruption by temporary states such as intoxication, fatigue, and emotional distress. Tests of these abilities have long been associated with constructs such as attention and executive functions [47-49] and there is evidence that suggests that processing speed and working memory capacity are essential precursors to fluid reasoning, both in terms of cognitive development $[50,51]$ and reasoning in real time [52,53].

Fluid reasoning can be directed toward acquiring new knowledge and skills, which, once acquired, tend to make future problem-solving more efficient ([15], pp. 138-152). The acquired knowledge factors-what Cattell [54] originally called crystallized intelligence and in a more differentiated form Horn called [4,26] expertise abilities—have at their center two highly correlated verbal abilities: Language development and familiarity with core knowledge domains that are highly valued by one's culture [55]. In the periphery, are increasingly less correlated specific knowledge domains that are acquired because of particular interests or vocational requirements [56]. Although literacy and numeracy were once the province of specialists, they are now core competencies in our culture and are highly correlated with verbal comprehension [57]. In different cultures and at different points in history, other skills might be more central markers of competence (e.g., herbal lore in rural Kenya [58]). Domain-specific acquired knowledge is speculated to have a structure that is similar to Holland's [59] RIASEC model of vocational interests $[30,56,60,61]$. 


\section{Hot Intelligence Theories}

\subsection{Early Descriptions of Hot Intelligences}

Although the term hot intelligence is fairly recent, numerous maxims and fables attest to the fact that thoughtful writers from antiquity understood that effective action often required insight about oneself (e.g., the Delphic maxim "Know thyself") and shrewd awareness of the motives of others (e.g., Aesop's advice to "Distrust interested advice") [62]. In the modern era, the first hot intelligence construct that received sustained attention from scholars was social intelligence ([63], pp. 258-259). As early as 1909 Dewey ([64], p. 43) defined it as "the power of observing and comprehending social situations". E. L. Thorndike [65], in an article published in Harper's Magazine for a lay audience in 1920, suggested social intelligence should have a place of prominence alongside abstract and mechanical abilities in his conceptualization of intelligence.

Although Thorndike himself did not develop his ideas about social intelligence much beyond argumentation and hypothesis, the idea was compelling enough that for decades scholars continued to work on the problem of finding good measures of it even in the face of persistently disappointing results. Initial hopes for the George Washington Test of Social Intelligence [66], an early measure of social intelligence, were dampened when validation efforts suggested that such tests were difficult to distinguish from verbal ability tests and offered little additional predictive utility beyond conventional ability tests [67-69]. Numerous subsequent attempts to produce useful measures of social intelligence were similarly unsuccessful [69-71].

Not all of the early work on social intelligence was unproductive, however. Notably, Guilford's [23,72] work in this domain convinced a previously very skeptical Cronbach ([73], p. 319) to soften his stance and re-open his mind toward the idea of social intelligence ([74], p. 343). In contrast to previous efforts, Guilford was able to show that his tests of behavioral cognition measured something clearly distinct from tests of verbal intelligence [75]. Guilford's work on social intelligence also found its way into Carroll's Three-Stratum Theory of Intelligence [9] as a narrow factor called Knowledge of Behavioral Content, though it was given a very "cool" interpretation as an aspect of knowledge and achievement.

\subsection{Present-Day Frameworks of Intelligences that Include Both Hot and Cool Intelligences}

Because of progress in recent decades, there is reason to believe that the enterprise of measuring social intelligence can be revived [76-78]. In particular, work on social intelligence has advanced substantially because scholars have increasingly focused on narrower constructs within social intelligence rather than social intelligence as a whole [79,80]. A small number of factor-analytic studies (e.g., [75,81-84]) have provided evidence for internally consistent hot intelligences that are distinct from cool intelligences.

If social intelligence is both a hot intelligence and an idea with scientific merit, how does it fit with more established theories in the cool intelligence domain? At least two prominent theories of intelligence have incorporated both kinds of constructs in a common framework.

In Gardner's Theory of Multiple Intelligences [85,86], the hot intelligences include two personal intelligences (Intrapersonal and Interpersonal Intelligence) and perhaps moral intelligence. These interact dynamically with more traditional cool intelligences (i.e., logical-mathematical, verbal-linguistic, and visual-spatial intelligence). Gardner's model also addresses aspects of intelligence that go well beyond the hot-cool dimension (i.e., musical, bodily-kinesthetic, naturalist, and existential intelligences).

Sternberg's Theory of Successful Intelligence $[87,88]$, like Gardner's theory, has an extremely broad scope. Although the hot-cool distinction is not its primary focus, it does incorporate elements that could be considered hot intelligences. In Sternberg's theory, there are three main components of intelligence: analytical, creative, and practical intelligence. Social intelligence is explicitly a facet 
of practical intelligence. However, hot abilities are not just isolated components in Sternberg's model but are interwoven in various places throughout the model. In particular, at the core of the theory is the idea that intelligence is directed toward success in achieving self-defined goals in a particular cultural context. Meeting one's own standards of success requires, among other things, enough social and self-understanding to capitalize on one's strengths and to compensate for one's weaknesses as one selects, shapes, and adapts to different (social) environments.

\subsection{Two Hot Intelligence Candidates for Integration with Cool Intelligence Models}

The diversity of theories within the hot intelligence domain makes it hard to say anything that would be true of all currently viable hot intelligence constructs. However, lessons learned from some cases may generalize to some, or even most others. For this reason, we will take two hot intelligence constructs as prototypes which may, to some degree, act as stand-ins for the domain as a whole. Even so, we acknowledge that often theoretical integration needs to proceed at the pace of one construct at a time.

Emotional intelligence is studied by many independent scholars and thus has more than one definition, but in the Mayer-Salovey-Caruso model $[80,89,90]$ it refers to the ability to perceive, understand, manage, and use emotions adaptively. This model of emotional intelligence has been supported by a wide variety of evidence $[3,91,92]$, though further refinements and elaborations may be needed to address various thoughtful criticisms [93].

Personal intelligence, a related hot intelligence construct recently proposed by Mayer [94], refers to the ability to perceive, understand, and use information about one's own and others' personality adaptively. The initial validation research suggests that personal intelligence may be a useful addition to a broad conceptualization of human intelligence [84,94-96]. We will address personal intelligence where possible, but much more is currently known about emotional intelligence.

\subsection{CHC Theory and the Hot Intelligences}

Compared to the breadth of Gardner's and Sternberg's theories, CHC Theory is more narrowly focused on the cool intelligences. Within the domain of the cool intelligences, CHC Theory is nonetheless a broad-ranging account of human intelligence. CHC Theory aims to be comprehensive but does not currently have any hot intelligence components (with the possible exception of the aforementioned and little-emphasized Knowledge of Behavioral Content factor, which is tentatively considered a specialized knowledge factor [39]). For this reason, recent work by MacCann, Joseph, Newman, and Roberts [81] on the relationship between CHC theory and emotional intelligence presents a kind of stress test for the possible expansion of $\mathrm{CHC}$ theory to include hot intelligences. In this study, more than 800 college students worked through an hours-long battery of tests measuring emotional intelligence [97] and CHC theory constructs. The authors' confirmatory factor analyses suggest that emotional intelligence can be considered a broad intelligence alongside other CHC broad abilities. In a reanalysis of the same data set, similar conclusions were reached by Legree and colleagues [98].

Putting emotional intelligence as a second-order broad factor in a tidy hierarchy may indeed be the proper conceptualization of emotional intelligence within the factor-analytic tradition. Perhaps Figure 2 needs a new column, with a cluster of hot intelligence broad abilities. However, chaos would ensue if taxonomies were amended every time a new study is published. Done properly, theoretical integration is hard work, requiring creativity and caution in equal measure. As there is no rush to commit to any firm conclusions, we believe that the MacCann et al. [81] study is a good prompt for reflection about what exactly broad abilities are and what a mature integration of hot and cool intelligences might look like. 


\section{Ability Taxonomies Need to Be Updated, But Carefully}

A good taxonomy should orient our attention to useful distinctions and should help us gloss over trivial differences [39]. Some mechanism needs to be in place for a taxonomy to be updated regularly or it calcifies and becomes increasingly irrelevant as new knowledge accumulates. However, because logical and intuitive distinctions among abilities are so easy to generate, putative broad abilities should be vetted thoroughly. Otherwise, as McNemar famously warned, there is the ever-present danger of letting a taxonomy degenerate "into more and more factors of less and less importance" ([99], p. 872).

In distinguishing among animals, it is perfectly reasonable to talk about animals that walk, animals that swim, and animals that fly. We can group animals by continent, by social structure, by mating habits, by diet, or by the climate in which they thrive. We can make an extremely large number of perfectly reasonable distinctions. However, taxonomists have mostly focused on classifying animals by their theorized evolutionary lineages, because doing so usefully and succinctly organizes many phenomena about animals that would otherwise be unexplained.

In a similar fashion, scholars have made all sorts of distinctions among cognitive abilities. Some abilities are associated with specific sensory modalities (visual, auditory, olfactory, gustatory, tactile, proprioceptive, and so forth) [15], others with particular kinds of symbolic content (verbal, numerical, and figural) [100]. Some abilities are defined by the rate at which a task can be done, others by the difficulty level of the task (speed vs. power) [9]. Some abilities are defined by giving a single correct response, others by generating many correct answers (convergent $v s$. divergent production) [23]. Some abilities require serial processing, others parallel processing (simultaneous vs. successive processing) [31].

Most of these distinctions are rationally derived and have intuitive appeal. In addition, they are often grounded in robust findings from neuropsychology and/or cognitive psychology. As long as these conceptual categories are not prematurely reified into causal agents, there is little harm in discussing them. However, taxonomies can suffer as much from too much imagination as from too little. At some point, the number of distinctions in the taxonomy makes the system too difficult to use and impossible to verify empirically. Theorizing, like all forms of creativity, thrives under properly balanced constraints.

In the factor-analytic tradition of intelligence theories, the constraints come in the form of correlation coefficients that must vary according to a particular structural model. However, obtaining a well-fitting structural model is only one step in a long process of construct validation research [101]. Although factor analysis can tell us that broad abilities exist, it does not easily reveal their number and nature. As Spearman ([8], pp. 222-223) stated:

We have now arrived at the "group factors" which have played such a baffling part in controversial writings. They make their appearance here, there, everywhere, nowhere; the very Puck of psychology. On all sides contentiously advocated, hardly one of them has received so much as a description, far less any serious investigation.

And yet they are of immense importance, not only theoretically, but also practically. By dint of nothing else can all those who claim to measure "special abilities"-holding out magnificent promises for industry—be saved from the charge of living in the fool's paradise of "faculties". For a test only measures any ability other than $g$ by having correlation with it other than that due to $g$.

We agree with Spearman that group factors (hereafter referred to as broad abilities) are of immense importance and that they warrant continued investigation. Although an enormous amount of work has been devoted to identifying which broad abilities exist, one suspects that Spearman would remain unsatisfied with how they are conceptualized today. Though the particulars of Spearman's theoretical work may not be particularly convincing today (e.g., the metaphor that $g$ is a mental energy and that specific abilities are mental engines), his ideas were the product of a sustained effort to give the $g$ factor a sophisticated philosophical treatment and precise psychological description [102]. Efforts 
like his have generally not been duplicated with the broad abilities. With the possible exception of working memory capacity [103], it is rare for researchers to attempt to describe broad abilities in terms of particular cognitive functions identifiable by cognitive psychological research. It is surprising that the idea of broad abilities has largely escaped the skepticism and close scrutiny that $g$ has been given for the last hundred years. Most arguments that cast doubt on the existence of $g$ apply equally to the major broad abilities (e.g., [17,104]). It makes little sense to overthrow a dictator if one's plan is to cede all power to petty warlords.

\section{Specific Proposal for Evaluating a New Broad Intelligence}

To assert that one must take emotions and other people's personalities into account if one is to behave intelligently when interacting with others is not the same as asserting that there exist theoretical entities such as emotional or personal intelligence. One might argue that identifying emotions, predicting others' behavior, and solving abstract logic puzzles are simply diverse manifestations of the same kind of intelligence. A proposed hot intelligence, such as emotional or personal intelligence, needs to meet a number of conceptual and empirical criteria in order to be accepted as a distinct broad intelligence. Our proposed criteria borrow extensively from similar lists laid out by Gardner [85] and Mayer et al. [90].

\subsection{The Content Domain of the Putative Broad Ability Must Be Clearly Laid Out}

A new ability need not have perfectly sharp theoretical boundaries-even if that were possible-, but researchers should be able to communicate about the ability sufficiently well that their findings can inform subsequent research about the ability. In particular, different teams of researchers should be able to create new measures of the construct based on a shared understanding of what it is. Specifying an intelligence's problem-solving domain is important because without a well-specified range of problems, test content to measure the intelligence cannot be developed with confidence.

Both personal and emotional intelligences have carefully worked-out problem-solving domains: for emotional intelligence it involves the capacity to reason accurately about (and with) emotions [90]; for personal intelligence, the capacity to reason accurately about personality [84]. Personality is defined as the organization of a person's major psychological subsystems including motivations and emotions, knowledge and intelligence, planning for action and preferred social styles, and awareness and self-control [95]. The problem-solving domains for both intelligences are further broken down into four areas for each intelligence, as indicated in Table 1.

Table 1. Do the personal and emotional intelligence meet standard criteria for an intelligence?

\begin{tabular}{ll}
\hline Personal Intelligence & Emotional Intelligence \\
\hline Well-specified problem-solving domain? $[90,95]$ & \\
- Identifying information about personality & - Perceiving emotions \\
- Forming models of personality & - Using emotions to enhance thought \\
$\begin{array}{ll}\text { - Guiding choices with personality-relevant } & \text { - Understanding emotions } \\
\text { information } & \text { - Mystematizing plans and goals }\end{array}$ \\
\hline
\end{tabular}


Table 1. Cont.

\begin{tabular}{l}
\hline Personal Intelligence \\
\hline Performance tests possible? \\
Problem-solving tasks include, for example, \\
identifying the behavior that often characterizes \\
a trait. For example, people can pair "stays late \\
at a party" with extraversion, and "is always on \\
time" with conscientiousness. \\
Veridical criteria possible? \\
Keyed to extensive empirical research in \\
personality, person-perception, etc.
\end{tabular}

Are there diverse kinds of problem-solving involved?

Nearly 13-18 different tasks were developed based on the problem area specification [84]; more such tasks are now under study.

Is the problem-solving domain unitary?

All tasks load on a principle factor, although models improve with the inclusion of subsidiary factors [84].

\section{Discriminant Validity}

The correlation with verbal intelligence is in the $r=0.35$ range; that with the Big Five is uniformly less than $r=0.30$ [84,96].

\section{Incremental Validity}

Personal intelligence predicts ability in liberal arts courses that demand reasoning about people at levels $2 \%-4 \%$ above that of SAT scores; it predicts the lack of counterproductive work behaviors at levels $2 \%-4 \%$ above a brief measure of verbal intelligence $[96,108,109]$.

Is it a second-stratum intelligence?

Personal intelligence appears as a broad-based mental ability that is used in a diverse range of problem-solving. As of yet, however, no large scale tests have been conducted with other broad intelligences.
Emotional Intelligence

Problem-solving tasks include, for example, understanding how a changing situation can change a person's emotion: for example, if a person learns that his friend was late because of an accident, his emotion might change from frustration to caring.

Keyed to the increasing number of empirically well-validated theories in the area $[105,106]$

Yes, a large and diverse number of tasks have been developed based on the problem-area specification $[90,95,105,107]$.

All tasks load on a principle factor, although models improve with the inclusion of subsidiary factors [81].

The correlation with verbal intelligence is in the $r=0.35$ range; that with the Big Five is uniformly less than $r=0.30$ [92].

There is evidence that emotional intelligence provides incremental validity in the prediction of many important outcomes [91,92].

There is factor-analytic evidence that EI is a broad intelligence at the same level as broad abilities in the cool intelligence domain [81].

\subsection{The New Construct Can Be Measured With Performance Tests}

To the degree that the construct is defined in terms of preferences and motivation, it lies outside the domain of intelligence. This is not to say that intelligence does not have important relationships with preferences and motivation. Indeed it does [110,111], but these relationships should be empirical, not definitional.

Performance tests are not the only valid method of assessing intelligence. Indeed many theories of intelligence are informed by a wide variety of non-test evidence (e.g., biographical analysis of eminent figures [85]). Nevertheless, performance tests are the most direct means of generating new data that can be used to evaluate testable claims. Although widely used, self-evaluations of emotional intelligence (e.g., the Bar-On EQ-i [112]) are indirect measures of the construct at best and overlap highly with other measures of personality such as the Big Five [113-115].

Performance test items are possible to write for both emotional and personal intelligences, as indicated by the development of ability scales in the area from a number of different laboratories. 
For example, the Mayer-Salovey-Caruso Emotional Intelligence Test and the Situational Test of Emotional Understanding are examples of performance measures of hot intelligences [106,116].

Some types of test items are scored according to consensus (i.e., most untrained raters agree), expert consensus (i.e., most trained raters agree), or veridical selection of correct answers (i.e., the answer is objectively true or false). Although a good argument can be made that consensual scoring provides a veridical criterion for many emotional intelligence items, e.g., [117], researchers prefer expert consensus and where possible veridical scoring approaches-the identification of a correct answer based on clear, widely accepted archival criteria. MacCann and Roberts' [105] Situational Tests of Emotional Understanding and Management both employ veridical scoring. The original MSCEIT [97] was scored using expert-consensus and consensus criteria, but the youth version employs veridical scoring [106].

\subsection{The New Construct Has Properties Similar to Established Cognitive Abilities}

All well-established cognitive abilities thus far identified develop with age and correlate positively with each other. It is extremely likely that newly identified abilities will do likewise. Emotional intelligence measures clearly have these properties [90-92] and initial evidence suggests that personal intelligence is likely to meet these criteria as well [84].

\subsection{The New Construct Should Be Measurable With Tests That Exhibit Convergent and Discriminant Validity}

If an ability exists, it should be possible to create methodologically diverse tests that exhibit convergent and discriminant validity, correlating substantially more highly with each other than they do with measures of other constructs [118]. That is, tests that correlate highly with each other are assumed to measure overlapping sets of psychological functions. Reliable tests with low correlations are assumed to measure relatively distinct abilities. This assumption may in certain cases prove to be false, but it is hard to dismiss its appeal as a starting point in theory construction. If it turned out that many types of memory test scores were uncorrelated, it would not mean that there is no such thing as memory-memory is too useful a concept to be undone by low correlations. However, such a finding would cast doubt on the idea of general memory ability and would suggest that averaging diverse memory test scores does not distill a unitary psychological function; it would merely be a summary score, and probably not a particularly useful one.

Rather than eyeballing correlation coefficients, convergent and discriminant validity is typically established with some form of covariance structure modeling (e.g., confirmatory factor analysis). Measurement models become increasingly convincing when each construct has multiple measures and model fit remains high [119-121].

Establishing that a construct has convergent and discriminant validity can take many twists and turns. If a study is designed specifically to distinguish between previously unidentified but plausible narrow factors, evidence for new factors is likely to emerge, though not necessarily exactly as hypothesized. Depending on which other variables are included in the dataset-and where the data analyst falls on the lumper/splitter continuum [122] — a particular broad ability might appear to merge with a close relative or to divide into two or more subfactors. A small subset of tests might cluster together in one battery of tests but might split apart when included in a more comprehensive battery. This does not mean that the question of a broad ability's existence is meaningless or hopelessly subjective, but that we should expect answers to vary from study to study and that the right answer will depend on our purpose. Thus, the question of whether a particular broad ability exists is not as straightforward as it might appear. From this perspective, broad abilities are not necessarily concrete entities but can instead be viewed as hierarchically arranged abstractions.

There are certainly many aspects of convergent and discriminant validity to be explored with respect to emotional and personal intelligence tests. However, the existing body of evidence suggests that it is possible to measure emotional intelligence with tests that display reasonable degrees of convergent and discriminant validity, comparable to tests in the cool intelligence 
domain [81,123-125]. Preliminary evidence on the convergent and discriminant validity of personal intelligence measures is likewise promising [84].

\subsection{The New Construct Predicts Important Outcomes Even After Accounting for More Established Cognitive Abilities}

An important check on the proliferation of categories has been suggested by Cattell ([126], p. 289). By disingenuously including groups of overly similar tests in a study, it is possible to make it appear that a test battery has whatever broad abilities one wants it to have. Abilities "discovered" this way are not true abilities but what Cattell called "bloated specifics". A bloated specific differs from a true ability in that it does not correlate with any external criteria worth studying. Thus, before a new ability is to be admitted into a theoretical taxonomy, it is not enough that a factor analysis supports its existence. That new factor must predict something that matters, above and beyond the other facets of intelligence. We are aware of no theory in which all of its parts have met this challenge fully, including Cattell's own.

Schneider and Newman [37] have pointed out that many broad intelligences increment prediction at levels between $2 \%$ and $6 \%$ of explained variance after accounting for general intelligence. Though this incremental predictive validity is often quite modest, by incorporating broad ability models it is possible to reduce adverse impact on historically disadvantaged populations in practical applications of intelligence testing [37,127,128].

Recent research indicates that personal intelligence predicts ability in liberal arts courses that demand reasoning about people at levels $2 \%-4 \%$ above that of SAT scores alone [96]. Personal intelligence also predicts (negatively) counterproductive work behaviors at levels slightly above a brief measure of verbal intelligence alone $[108,109]$. Numerous reviews describe the incremental prediction of performance measures of emotional intelligence above traditional measures of intelligence alone [91,92]. A forthcoming issue of Emotion Review will provide an update.

\subsection{The New Construct Should Be Linked to Specific Neural Modules That Evolved to Help Humans Survive and Reproduce}

The criterion that specific intelligences must be linked to specific neural modules has played in important role in Gardner's Theory of Multiple Intelligences [85]. Without this criterion, almost any useful skill could be dubbed a new intelligence. For example, computer skills are becoming increasingly important; modern economies shower money on those who can intelligently exploit what computers have to offer. Is there a digital intelligence? Answering yes stretches the meaning of intelligence far beyond its traditional boundaries. Computer skills have no plausible evolutionary history. Natural selection has not had time to evolve special cognitive functions that help humans use computers to survive and reproduce. The intelligent use of computers relies exclusively on repurposing cognitive functions that evolved previously to solve other problems of survival and reproduction.

Do emotional and personal intelligence satisfy this criterion? Easily. Many psychologists have remarked, for example, about how important it was for our evolutionary ancestors to understand and predict the behavior of the people around them. Dunbar [129] has proposed the social brain hypothesis to explain that human beings increased in their mental capacities precisely so as to talk and keep track of one another in their ancient groups; by being able to do so, humans increased the size of their societies with consequential benefits. As they spoke about one another, they communicated about individual differences, according to Buss [130] who has suggested that we also have evolved neural modules that allow us to detect individual differences in one another. Such detection systems allowed our ancestors to choose whom they would hunt with, work with and mate with. Those who made better choices increased their likelihood of survival and reproduction.

Research that maps specific aspects of emotional intelligence to specific neural modules is still in a preliminary stage. However, there is evidence that lesions in specific regions of the brain 
are differentially associated with specific factors within emotional intelligence as measured by the MSCEIT [131-133].

\section{Alternative Interpretations of the Broad Ability Concept}

If the criteria above define an intelligence-then what distinguishes a broad intelligence from general intelligence on the one hand, or specific abilities on the other? We grapple with this issue here. This has practical implications: If the task is to show that hot intelligences such as emotional intelligence and personal intelligence are broad factors of intelligence, it is hard to know what to aim for, as there is no strong theory as to exactly what the broad abilities are. It appears that the term refers to many different kinds of theoretical constructs, not all of which are mutually exclusive. That is, there is no guarantee that abilities that we currently consider broad abilities are abilities of the same type. Some types of broad abilities may not be amenable to evaluation via factor analysis (or may not appear to be "real" when the attempt is made). Distinguishing between different types of broad abilities may facilitate communication between researchers from different traditions. When an ability construct does not conform to factor analytic models, it might still be a valid concept but of a different kind, which may put limits on what can be claimed about the construct (e.g., that one can create summary scores of the ability by summing marker indicator variables).

As we describe each alternative, we discuss how it might apply to the two hot intelligences that are the focus of this article.

\subsection{Broad Abilities as Discrete Functions of the Mind with Broad Applicability}

As we consider the integration of broad intelligences, it is worth reflecting on the fuzziness of the distinction between broad and narrow mental abilities. There are no natural joints to carve in continuous dimensions like breadth. Many hierarchical models of intelligence allow for intermediate levels between broad and narrow abilities [28]. Nevertheless, there are aspects of ability that are clearly quite broad and others that are very narrow. For example, the ability to read written communications-from novels to instruction manuals - and the ability to speak Pig Latin fluently are both fairly discrete abilities. However, the ability to read and comprehend is broader because it is useful in many important aspects of modern life whereas the ability to speak Pig Latin is not. If the core of fluid intelligence is a general relation-perceiving function of the mind-what Spearman [102] termed the eduction of relations and correlations - then fluid intelligence is a broad ability in this sense. It is a discrete function that is useful in diverse situations.

Broad abilities in this sense define discrete functions; Applying this criterion to personal and emotional intelligence raises questions as to their status: Although they are broadly useful, they may not be discrete-for example, the degree to which they overlap with one another and with social intelligence has yet to be determined, and what evidence there is suggests that personal intelligence may subsume emotional intelligence [95].

\subsection{Broad Abilities as Sets of "Entangled" Narrow Abilities}

Some broad abilities may be discrete functions whereas others may be constructs of a very different sort. Just because a factor analysis allows one to draw an ellipse linked to many abilities does not mean that the ellipse represents a unitary function. Certain habits of data analysis used mindlessly can obscure viable theoretical alternatives. For example, although the wide variety of factor rotation options available to researchers are in many ways mathematically equivalent, they are not theoretically equivalent. In Figure 3, there are three models that perfectly explain the same correlation matrix. The oblique rotation at the top implies that although the two latent abilities are correlated (for reasons unspecified), changes in one ability will have no direct effect on the indicators of the other ability. It is likely that the structure of knowledge domains operates in this way ([15], p. 97). People who know a lot about the early Roman Republic probably also know more than the average person about the First World War. However, reading a book about either one of those topics is unlikely to directly increase 
one's knowledge of the other. To be sure, learning certain underlying patterns and historical insights from one era might facilitate learning in another-but hearing the stories of Lucretia or Cincinnatus does not make one directly familiar with the Schlieffen Plan or In Flanders Fields. With such a model, it is the theorist's job to explain how abilities with no direct causal links came to be correlated.

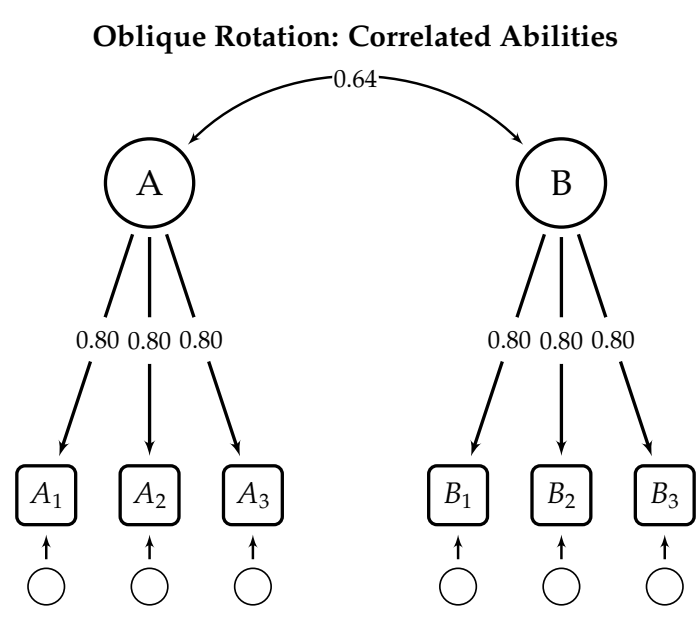

Partially Entangled Abilities

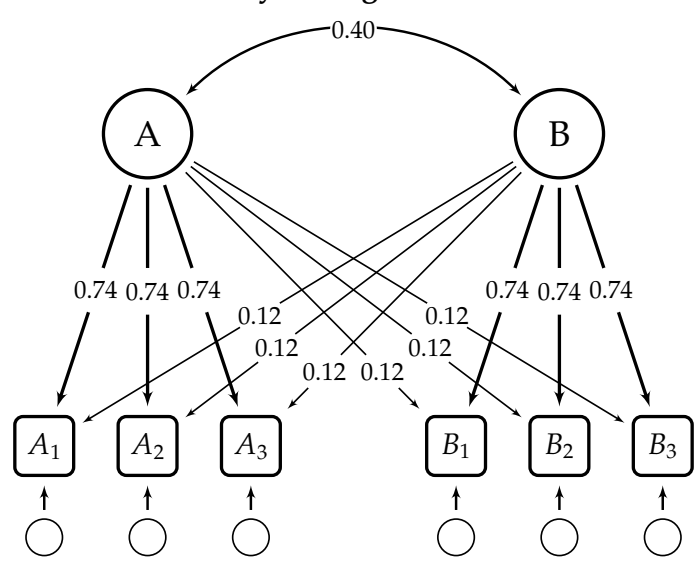

Orthogonal Rotation: Entangled Abilities

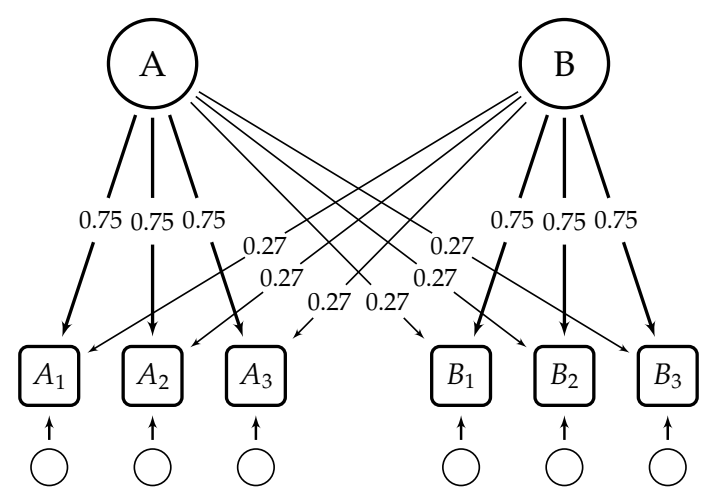

Figure 3. Different rotations imply different causal models. 
The orthogonal model at the bottom of Figure 3 implies that the two latent abilities are uncorrelated, yet are "entangled" by small cross-loadings. That is, it is difficult to measure certain cognitive functions without simultaneously measuring others. Performance on each test is influenced directly by both abilities, though to differing degrees. Complex visual-spatial tasks like the Block Design subtest from the Wechsler tests appear to utilize a complex mix of narrow cognitive abilities that are relied upon to different degrees in different individuals [134]. Although visualization and mental rotation speed are statistically distinguishable, it is hard to imagine how a test could be devised such that mental rotation speed is measured with no involvement of visualization ([9], p. 325). Thus, mental rotation might be "entangled" with visualization in the same way that soccer is entangled with running ability.

It is worth noting that there is no reason that mental abilities are either merely correlated or exclusively entangled. In the second model in Figure 3, the abilities are correlated but also have small cross-loadings. As an aside, this model effectively illustrates how excluding "small" cross-loadings in the indicator variables can drastically distort the structural relations among the latent variables [135]. It seems unlikely that traditional cross-sectional factor-analytic studies could distinguish among the three models in Figure 3. It is possible that studies of individuals with brain lesions, long-term longitudinal studies, or studies in which abilities are experimentally manipulated might be required to sort out such relationships. It is unlikely that these questions will be settled any time soon for either hot or cool abilities. However if one mindlessly rotates all models to simple structure, certain viable alternatives will never be investigated.

It is possible that the various narrow factors within personal, emotional, and social intelligence are similarly "entangled" in complex ways. For example, on the MCSEIT, the Understanding Emotions and Managing Emotions factors have a substantial residual correlation even after accounting for the general emotional intelligence factor [136]. One way to explain the residual correlation is to posit existence of an intermediate factor (Strategic EI) between the narrow abilities and the broad ability [97]. However, higher-order structures are not the only way to explain residual correlations. An alternative possibility that avoids "multiplying entities needlessly" is that Understanding and Managing emotions are distinct but entangled because managing emotions always involves some degree of understanding them. Distinguishing between these two possibilities (or many others not stated here) will require study designs more complex and deliberate than traditional cross-sectional factor-analytic studies.

\subsection{Broad Abilities as Essential Precursors to Many Other Abilities}

The ability to see is broad in the sense that it is an essential ingredient in many other abilities (though sight-impaired individuals routinely show that the lack of sight is not as limiting as many suppose). The ability to whistle is a precursor to far fewer abilities. Working memory capacity is a broad ability in this sense, because it is a relatively unified domain-general capacity that is an essential ingredient in many other abilities_fluid reasoning in particular [137].

Again, although emotional and personal intelligence are thought to consist of discrete abilities, they are not discrete abilities themselves. Thus, they are probably not characterized as broad abilities in this sense. To be sure, they are probably essential ingredients, in aggregate, of other abilities, such as the ability to anticipate the behavior of others, lead groups, understand humor, and so forth.

\subsection{Broad Abilities as Conceptual Categories}

Some constructs are just that: constructed. Koalas, pandas, and Teddies have enough similarities to share the name bear, but it is clear that there is nothing fundamental that links them as a distinct group. Sometimes for reasons of conceptual economy certain groupings of abilities are made because they share certain features, not because they are causally related. For example, in Figure 2, the perceptual abilities $(\mathrm{Gv}, \mathrm{Ga}$, etc.) are similar in that they are clusters of modality-specific narrow abilities but there is no implication of a general perceptual ability separate from the general factor of intelligence. 
If emotional intelligence were simply a diverse collection of abilities that happen to have something to do with emotion, one could imagine reallocating the specific abilities to other categories in Figure 2. For example, the ability to produce specific emotional facial expressions on demand (as actors do) might be just a specific psychomotor ability. The ability to perceive emotions accurately would take its place among other perceptual abilities. Managing emotions might be a manifestation of the executive control of attention. Understanding emotions would be a specific knowledge factor.

Although it is certainly possible that specific components of emotional intelligence might have special relationships with other cool abilities, studies on the convergent and discriminant validity of personal and emotional intelligence tests $[81,84]$ suggest that neither hot intelligence construct is a mere conceptual category. Convergent and discriminant validity studies are necessary but not sufficient to be able to make the strong claim that a construct is not just a conceptual category. Borsboom [138] notes that even if individual differences are strongly correlated, it does not follow that there is necessarily a theoretically important entity within individuals that connects them. For example, a factor analysis of physical abilities among Norwegians might reveal a small factor consisting of rifle shooting accuracy and cross-country skiing endurance. Before we theorize about an ability construct that explains the link between these two disparate skills, we would do well to consider the popularity of the Biathlon event in Norway. Factor analysis alone cannot distinguish between variables that load together because of an underlying ability or variables that load together because of specific cultural practices.

With respect to cognitive abilities, Vernon ([22], p. 8) warned:

...it should be clear that a factor is a construct which accounts for the objectively determined correlations between tests, in contrast to a faculty which is a hypothetical mental power. We can if we wish go on to theorize about the psychological nature and origin of factors. Better, we can conduct experiments to discover just what performances involve a factor, among which groups of people it emerges, and what conditions affect it. But factors should be regarded primarily as categories for classifying mental or behavioural performances, rather than as entities in the mind or nervous system.

This is essentially the argument Horn invokes to criticize the theory of general intelligence [17]. Yes, it emerges in a factor analysis, but its indicators do not respond the same way to developmental influences, which to Horn meant that it is not a unitary ability. Cattell ([15], pp. 12-13) offers sound guidance to researchers hoping to show that a construct is not merely a collection of correlated variables:

If we have a phrase like "the capacity to abstract", there is a tendency, as Francis Bacon warned us back in Elizabethan times, automatically to assume from a single term that there is a single thing. [...]

To appreciate the importance of this, one must first acquire a deep suspicion of words. [...] In physical life we do not often go wrong about and are seldom asked to prove our intuitive belief that the cat is one object and the dog another. But in the vast jungle of observation which is behavior-the substance of psychology-the taxonomist has to become a far more sophisticated methodologist than in almost any other science. What in fact do we mean, and how do we prove it, when we assert, say, that "musical aptitude" is a unitary gift?

The basic rule for proving the unity of an entity is the same (as John Stuart Mill explained) regardless of whether it is [a] physical or behavioral unity. A thing is a unity when its parts move together, change together, and respond together to some treatment or stimulation. The cat and dog may be an amicable heap by the fireside, but when you call the dog, four legs, two ears, a nose, and a tail cross the room to you at once while the other, cat-like elements stay put.

Direct experimental evidence of this sort is not yet available for most of the cool intelligence broad abilities, so it is not surprising that it is also unavailable for the hot intelligences. As an example of this 
kind of research, visual-spatial ability appears to respond to natural fluctuations and experimental manipulations of testosterone in humans and other mammals [139]. However, it is not yet clear if testosterone influences mainly mental rotation or all facets of visual-spatial ability equally [140].

Evidence of this sort is difficult to collect but not impossible with the hot intelligences. For example, suppose that interventions designed to improve emotion recognition accuracy (i.e., the Perceiving Emotions factor) caused the remaining untargeted emotional intelligence abilities to rise in a pattern consistent with existing structural models of emotional intelligence. Likewise, suppose that brain injuries that interfered with emotion recognition accuracy were associated with a similar pattern of change in other narrow emotional intelligence abilities but in the opposite direction. This kind of evidence would suggest that emotional intelligence is not a mere conceptual category, but a set of causally integrated functions of the mind.

\subsection{Broad Abilities as Collective Properties}

A collective property is a feature that emerges from the measurement of many objects. For example, the sample mean is not in the sample, it is a collective property of the sample. Even though some numbers in the sample might have the same value as the sample mean, they are not conceptually the same thing as the sample mean. More concretely, if you look for "the economy", you will not find it in your wallet, or in a bank, or at a stock exchange. It is a collective property, an aggregate of countless voluntary exchanges humans make to meet their needs and fulfill their wants. Racial diversity in the classroom is not found in any particular student but is a collective property of the group. To say that a particular student adds to the racial diversity of a classroom is not so much a statement about the student but about the current composition of the class as a whole.

Bartholomew ([141], p. 91 ) suggests that the general factor of intelligence is a collective property of a large number of features of the brain. Surprisingly, this appears to have been the position Spearman [142] himself took. Jensen, too, believed that $g$ is not a reified ability itself, but a result from the sum total of all forces that cause abilities within the same person to be more similar to each other than they otherwise would have been ([143], p. 29). This argument is easily extended to the broad abilities. Perhaps broad abilities, too, are collective properties-useful and informative properties, to be sure-but not tangible objects. That is, they are not abilities themselves but result from the total effects of all influences that make the narrow abilities within a domain more similar to each other than they would be by chance. This should not give comfort to obscurantists who do not wish any actual measurements of intelligence to occur. Collective properties (e.g., sample means, economic indicators, and racial diversity) are routinely measured and studied.

If emotional intelligence is a collective property of many narrow abilities related to emotions, we should not expect to find a single ability among them that is the broad ability any more than we should expect to find the sample mean literally in our data, the economy literally in our wallet, or racial diversity in particular students. If emotional intelligence is a collective property of some sort, it will be found in the aggregate of countless forces and influences that shape how we perceive, understand, manage, and use emotions. Framed this way, for example, emotional perception per se is not the proper object of study, but rather the proximal influences that cause emotional perception abilities to correlate as they do with each other and with other aspects of emotional intelligence.

\subsection{Broad Abilities as Causal Systems}

Borsboom [138] distinguished between latent variable models and causal systems. Traditional hierarchical factor-analytic models similar to Figure 1 imply that narrow abilities have no relationships with each other after controlling for broader abilities. In a causal system model, narrow abilities influence each other directly in sometimes complex networks of association $[45,144]$. Thus, broad abilities are not so much "things" (i.e., discrete entities) as they are relatively integrated portions of a large network of abilities. 
The ability to store information in working memory is a broad ability in this sense because it refers to a collection of interdependent narrow abilities. For example, it is reasonably clear that there are different subsystems of working memory that handle different kinds of sensory codes and different mechanisms for updating the contents of short-term memory [103]. If working memory consists of many sub-abilities, why is it legitimate to refer to working memory as a whole? It is legitimate to talk about a car's engine as single thing, even though the engine is just a collection of many parts, because the parts accomplish a function together that none of them could accomplish alone. Likewise, the various components of working memory form a functional unity in that they facilitate complex mental functions such as planning and reasoning [137].

In Figure 4, two different models of emotional intelligence are contrasted. On the left, emotional intelligence is an influence on the specific abilities. On the right, emotional intelligence is not an entity in the causal system, it is the causal system ( $c f$. [145]). That is, emotional intelligence, in this view, is an interlocking system of emotion-related abilities. This model is fashioned after an information-processing model in which perceptions are inputs and actions are outputs. Obviously, much more complex models are possible and plausible. A similar model of the subcomponents of personal intelligence could be constructed as well.

Emotional Intelligence as a Latent Variable

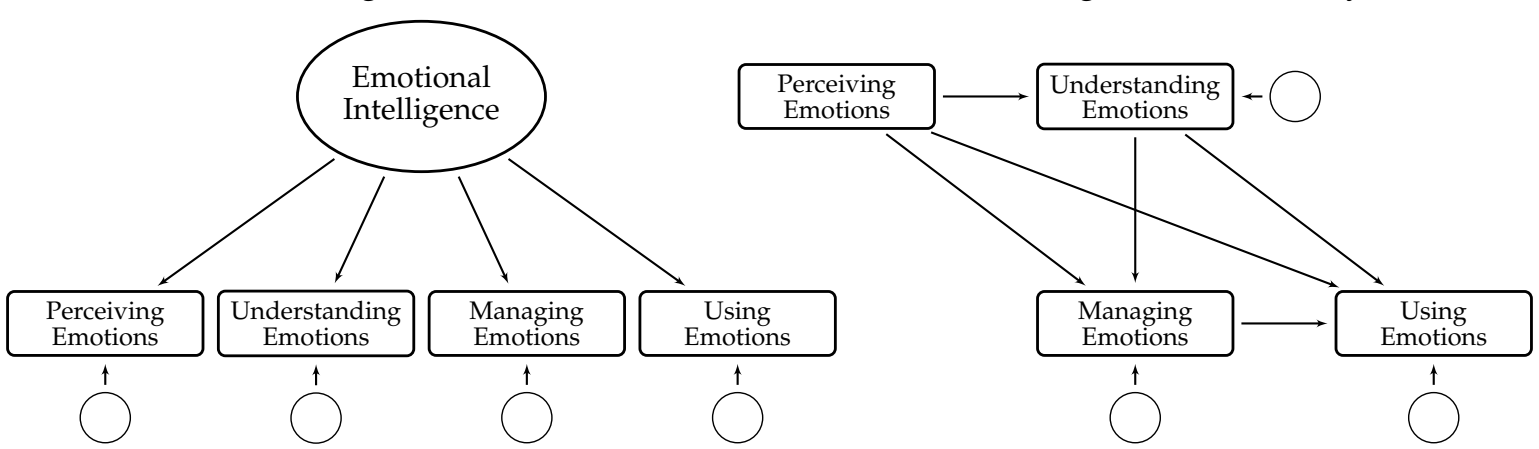

Figure 4. If the causal system model is an oversimplification, is not the latent variable model even more so?

If this view of hot intelligences as causal systems has merit, it could be integrated into larger information processing models of intelligence [45]. In Figure 5, we present a very simple integration of emotional intelligence and some of the broad abilities within CHC Theory. No strong claims are being made in Figure 5. Rather, this is merely the sort of model that might emerge from attempts to integrate hot and cool intelligences viewed as complex causal systems. Each broad ability is a set of narrow abilities that are causally linked, probably in ways much more complex than are depicted in Figure 5. The linkages among the CHC constructs are inspired by Cattell's investment theory ([15], p. 139) and by Fry and Hale's developmental cascade hypothesis [50,51].

In broad strokes, one could imagine that the Perceiving Emotions component of emotional intelligence would have a greater affiliation with perceptual abilities than with the other components of emotional intelligence. For example visual-spatial processing $(\mathrm{Gv})$ might facilitate facial expression recognition, and auditory processing $(\mathrm{Ga})$ might do likewise with emotional cues in the vocal channel. The Understanding Emotions component might have a greater relationship with verbal knowledge than would the other components of emotional intelligence. The Managing Emotions component might have a special relationship with the attentional control functions of working memory and processing speed. The Using Emotions to Facilitate Thought component might influence the kinds of reasoning measured by fluid and crystallized intelligence tests. The emotional intelligence system as a whole might help explain why some people persist in acquiring knowledge when it is difficult (or boring) whereas others give up prematurely. All of these linkages between hot and cool intelligence are quite speculative, but this is a potentially fruitful line of research. 


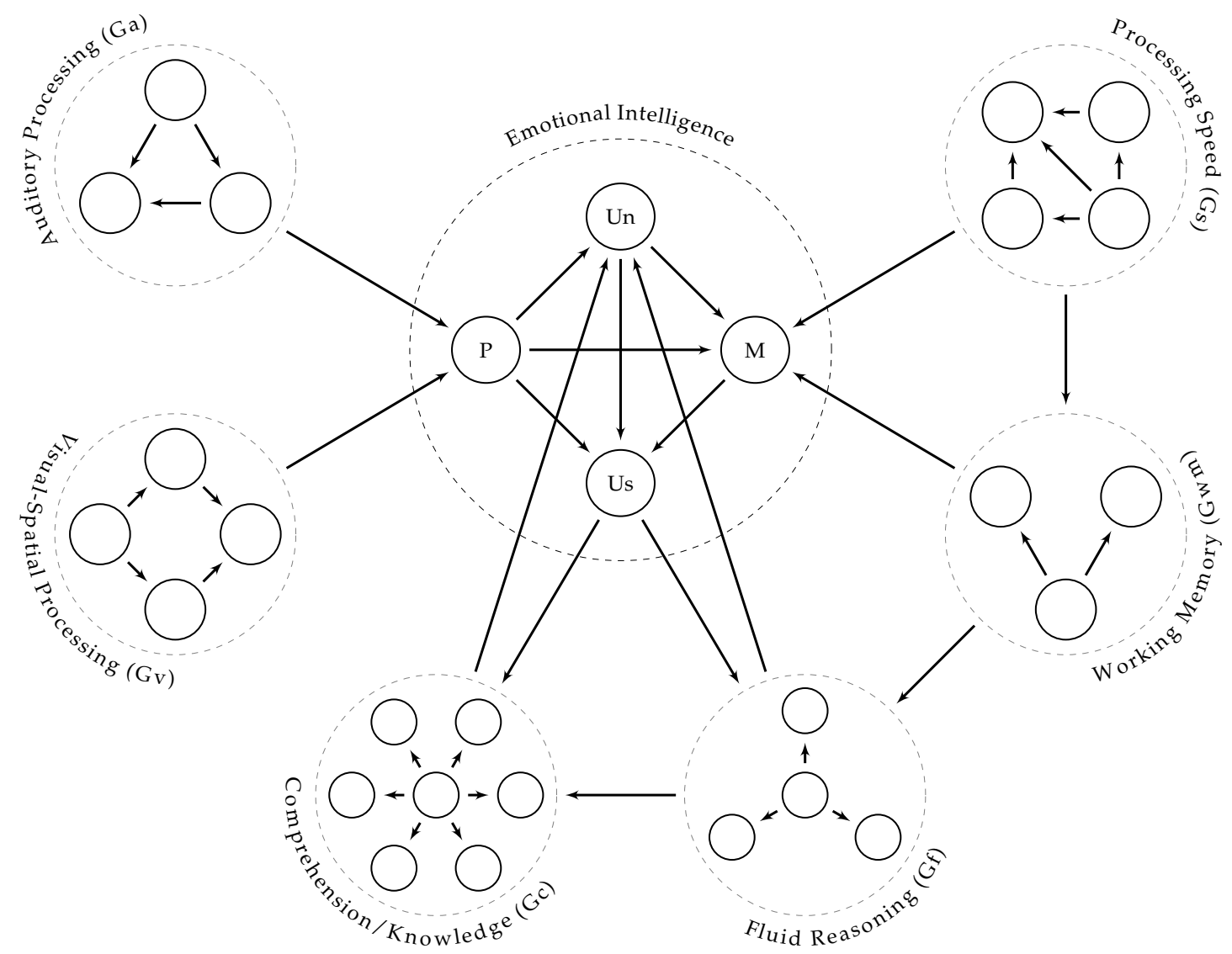

Figure 5. Emotional Intelligence and Cattell-Horn-Carroll Broad Abilities as Interdependent Causal Systems. $\mathrm{P}=$ Perceiving Emotions, Un = Understanding Emotions, $\mathrm{M}=$ Managing Emotions, Us = Using Emotions to Enhance Thought.

\section{Conclusions}

Schneider and Newman [37] presented multiple reasons to study broad intelligences, including: (a) models that take them into account offer better fit to empirical data; (b) they increment prediction of outcomes; and (c) their use has the potential to reduce adverse impact on historically disadvantaged minority populations. Building on these arguments, in the present paper we have outlined key features of broad intelligences so as to strengthen the conception of what they are and how they operate. We have speculated on the relations they have among one another and with other intelligences, and also paid special attention to how a new realm of hot intelligences might fit in with the cool. We hope such conceptions will pave the way for future research in the area.

Author Contributions: All three authors were equally involved in the planning and overall conceptualization of the article. The initial draft was completed by W. Joel Schneider. Table 1 and many paragraphs of the initial draft were written by John D. Mayer. John D. Mayer and Daniel A. Newman reviewed and substantially revised the initial draft. 
Conflicts of Interest: The authors declare no conflict of interest.

\section{References}

1. Wilson, E. Consilience: The Unity of knowledge; Vintage Books: New York, NY, USA, 1999.

2. Mayer, J.D. Personal intelligence. Imagin. Cogn. Personal. 2008, 27, 209-232.

3. Mayer, J.D.; Salovey, P.; Caruso, D.R.; Cherkasskiy, L. Emotional intelligence. In The Cambridge Handbook of Intelligence; Sternberg, R.J., Kaufman, S.B., Eds.; Cambridge University Press: New York, NY, USA, 2011; pp. 528-549.

4. Horn, J.L.; Noll, J. Human cognitive capabilities: Gf-Gc theory. In Contemporary Intellectual Assessment: Theories, Tests and Issues; Flanagan, D.P., Genshaft, J.L., Harrison, P.L., Eds.; Guilford Press: New York, NY, USA, 1997; pp. 53-91.

5. Brown, M. How I Killed Pluto and Why It Had It Coming; Spiegel \& Grau: New York, NY, USA, 2012.

6. Neisser, U.; Boodoo, G.; Bouchard, T.J., Jr; Boykin, A.W.; Brody, N.; Ceci, S.J.; Halpern, D.F.; Loehlin, J.C.; Perloff, R.; Sternberg, R.J.; et al. Intelligence: Knowns and unknowns. Am. Psychol. 1996, 51, 77-101.

7. Spearman, C.E. "General intelligence," objectively determined and measured. Am. J. Psychol. 1904, 15, 201-292.

8. Spearman, C.E. The Abilities of Man: Their Nature and Measurement; MacMillan: London, UK, 1927.

9. Carroll, J.B. Human Cognitive Abilities: A Survey of Factor-Analytic Studies; Cambridge University Press: New York, NY, USA, 1993.

10. Binet, A. Spearman, the proof and measurement of association between two things and general intelligence objectively determined and measured. L'Année Psychol. 1905, 11, 623-624.

11. Thomson, G.H. A hierarchy without a general factor. Br. J. Psychol. 1916, 8, 271-281.

12. Ruml, B. The need for an examination of certain hypotheses in mental tests. J. Philos. Psychol. Sci. Methods 1920, 17, 57-61.

13. Burt, C. Experimental tests of general intelligence. Br. J. Psychol. 1909, 3, 94-177.

14. Stern, W. The Psychological Methods of Testing Intelligence; Warwick \& York: Baltimore, MD, USA, 1914.

15. Cattell, R.B. Intelligence: Its Structure, Growth and Action; Elsevier: New York, NY, USA, 1987.

16. Spearman, C.E.; Wynn Jones, L. Human Ability: A Continuation of "The Abilities of Man"; Macmillan: London, UK, 1950.

17. Horn, J.L.; McArdle, J.J. Understanding human intelligence since Spearman. In Factor Analysis at 100: Historical dEvelopments and Future Directions; Cudeck, R., MacCallum, R.C., Eds.; Routledge: Mahwah, NJ, USA, 2007; pp. 767-782.

18. Carroll, J.B. The Higher-stratum Structure of Cognitive Abilities: Current Evidence Supports $g$ and About Ten Broad Factors. In The Scientific Study Of General Intelligence: Tribute to Arthur R. Jensen; Nyborg, H., Ed.; Pergamon: Amsterdam, the Netherlands, 2003; pp. 5-22.

19. Thurstone, L.L. The vectors of mind. Psychol. Rev. 1934, 41,1-34.

20. Thurstone, L.L. The Vectors of Mind: Multiple-Factor Analysis for the Isolation of Primary Traits; University of Chicago Press: Chicago, IL, USA, 1935.

21. Thurstone, L.L. Primary Mental Abilities; University of Chicago Press: Chicago, IL, USA, 1938.

22. Vernon, P. The Structure of Human Abilities; Wiley: New York, NY, USA, 1950.

23. Guilford, J.P. The Nature of Human Intelligence; McGraw-Hill: New York, NY, USA, 1967.

24. French, J.W.; Ekstrom, R.B.; Price, L.A. Manual for Kit of Reference Tests for Cognitive Factors (Revised 1963); Educational Testing Service: Princeton, NJ, USA, 1963.

25. Ekstrom, R.B.; French, J.W.; Harman, H.H.; Dermen, D. Kit of Factor-Referenced Cognitive Tests; Educational Testing Service: Princeton, NJ, USA, 1976.

26. Horn, J.L.; Blankson, N. Foundations for better understanding of cognitive abilities. In Contemporary Intellectual Assessment. Theories, Tests, and Issues, 2nd ed.; Harrison, P.L., Flanagan, D.P., Ed.; Guilford Press: New York, NY, USA, 2005; pp. 41-68.

27. McGrew, K.S. CHC theory and the human cognitive abilities project: Standing on the shoulders of the giants of psychometric intelligence research. Intelligence 2009, 37, 1-10. 
28. Schneider, W.J.; Flanagan, D.P. The relationship between theories of intelligence and intelligence tests. In Handbook of Intelligence: Evolutionary Theory, Historical Perspective, and Current Concepts; Goldstein, S., Princiotta, D., Naglieri, J.A., Eds.; Springer: New York, NY, USA, 2015; pp. 317-340.

29. Jäger, A.O. Intelligenzstrukturforschung: Konkurrierende Modelle, neue Entwicklungen, Perspektiven. Psychol. Rundsch. 1984, 21, 21-35. (In German)

30. Ackerman, P.L. A theory of adult intellectual development: Process, personality, interests, and knowledge. Intelligence 1996, 22, 227-257.

31. Das, J.P.; Naglieri, J.A.; Kirby, J.R. Assessment of Cognitive Processes: The PASS Theory of Intelligence; Allyn \& Bacon: Boston, MA, USA, 1994.

32. Johnson, W.; Bouchard, T.J. The structure of human intelligence: It is verbal, perceptual, and image rotation (VPR), not fluid and crystallized. Intelligence 2005, 33, 393-416.

33. McGrew, K.S. The Cattell-Horn-Carroll Theory of Cognitive Abilities: Past, Present, and Future. In Contemporary Intellectual Assessment. Theories, tEsts, and Issues, 2nd ed.; Harrison, P.L., Flanagan, D.P., Ed.; Guilford Press: New York, NY, USA, 2005; pp. 136-181.

34. Beauducel, A.; Kersting, M. Fluid and crystallized intelligence and the Berlin Model of Intelligence Structure (BIS). Eur. J. Psychol. Assess. 2002, 18, 97-112.

35. Flanagan, D.P.; Alfonso, V.C.; Dixon, S.G. Cross-battery approach to the assessment of executive functions. In Handbook of Executive Functioning; Goldstein, S., Naglieri, J., Eds.; Springer: New York, NY, USA, 2014; pp. 379-409.

36. Kaufman, A.S.; Kaufman, N.L. Kaufman Assessment Battery for Children-Second Edition (KABC-II); American Guidance Service: Pines, MN, USA, 2004.

37. Schneider, W.J.; Newman, D.A. Intelligence is multidimensional: Theoretical review and implications of specific cognitive abilities. Human Resour. Manag. Rev. 2015, 25, 12-27.

38. McGrew, K.S. Analysis of the major intelligence batteries according to a proposed comprehensive Gf-Gc framework. In Contemporary Intellectual Assessment: Theories, Tests, and Issues; Flanagan, D.P., Genshaft, J.L., Harrison, P.L., Eds.; Guilford Press: New York, NY, USA, 1997; pp. 151-179.

39. Schneider, W.J.; McGrew, K.S. The Cattell-Horn-Carroll model of intelligence. In Contemporary Intellectual Assessment: Theories, Tests and Issues, 3rd ed.; Flanagan, D.P., Harrison, P.L., Eds.; Guilford Press: New York, NY, USA, 2012; pp. 99-144.

40. McGrew, K.S.; LaForte, E.M.; Schrank, F.A. Woodcock-Johnson IV Technical Manual; Riverside: Rolling Meadows, IL, USA, 2014.

41. Sternberg, R.J. Intelligence. Wiley Interdiscip. Rev. Cogn. Sci. 2012, 3, 501-511.

42. Kaufman, A.S. IQ Testing 101; The Psych 101 series; Springer Publishing Company: New York, NY, USA, 2009.

43. Alfonso, V.C.; Flanagan, D.P.; Radwan, S. The impact of the Cattell-Horn-Carroll Theory on Test Development and Interpretation of Cognitive and Academic Abilities. In Contemporary Intellectual Assessment: Theories, Tests, and Issues, 2nd ed.; Flanagan, D.P., Harrison, P.L., Eds.; Guilford Press: New York, NY, USA, 2005; pp. 185-202.

44. Woodcock, R.W. An information processing view of the Gf-Gc theory. J. Psychoeduc. Assess. 1993, 8, $231-258$.

45. Schneider, W.J.; McGrew, K.S. Cognitive performance models: Individual differences in the ability to process information. In Handbook of Educational Theories; Irby, B., Brown, G., Laro-Alecio, R., Jackson, S., Eds.; Information Age Publishing: Charlotte, NC, USA, 2013; pp. 767-782.

46. Chun, M.M.; Golomb, J.D.; Turk-Browne, N.B. A taxonomy of external and internal attention. Annu. Rev. Psychol. 2011, 62, 73-101.

47. McCloskey, G.; Perkins, L. Essentials of Executive Function Assessment; Wiley: Hoboken, NJ, USA, 2012.

48. Mirsky, A.F.; Anthony, B.J.; Duncan, C.C.; Ahearn, M.B.; Kellam, S.G. Analysis of the elements of attention: A neuropsychological approach. Neuropsychol. Rev. 1991, 2, 109-145.

49. Miller, D.C. Essentials of School Neuropsychology, 2nd ed.; Wiley: Hoboken, NJ, USA, 2013.

50. Fry, A.F.; Hale, S. Processing speed, working memory, and fluid intelligence: Evidence for a developmental cascade. Psychol. Sci. 1996, 7, 237-241.

51. Kail, R.V. Longitudinal evidence that increases in processing speed and working memory enhance children's reasoning. Psychol. Sci. 2007, 18, 312-313. 
52. Krumm, S.; Schmidt-Atzert, L.; Buehner, M.; Ziegler, M.; Michalczyk, K.; Arrow, K. Storage and non-storage components of working memory predicting reasoning: A simultaneous examination of a wide range of ability factors. Intelligence 2009, 37, 347-364.

53. Dang, C.P.; Braeken, J.; Colom, R.; Ferrer, E.; Liu, C. Do processing speed and short-term storage exhaust the relation between working memory capacity and intelligence? Personal. Individ. Differ. 2015, 74, 241-247.

54. Cattell, R.B. The measurement of adult intelligence. Psychol. Bull. 1943, 40, 153-193.

55. Schipolowski, S.; Wilhelm, O.; Schroeders, U. On the nature of crystallized intelligence: The relationship between verbal ability and factual knowledge. Intelligence 2014, 46, 156-168.

56. Ackerman, P.L. Domain-specific knowledge as the "dark matter" of adult intelligence: Gf/Gc, personality and interest correlates. J. Gerontol. Ser. B Psychol. Sci. Soc. Sci. 2000, 55, 69-84.

57. Schneider, W.J. Principles of Assessment of Aptitude and Achievement. In The Oxford Handbook of Child Psychological Assessment; Saklofske, D., Reynolds, C., Schwean, V., Eds.; Oxford University Press: New York, NY, USA, 2013; pp. 286-330.

58. Sternberg, R.J.; Nokes, C.; Geissler, P.W.; Prince, R.; Okatcha, F.; Bundy, D.A.; Grigorenko, E.L. The relationship between academic and practical intelligence: A case study in Kenya. Intelligence 2001, 29, 401-418.

59. Holland, J.L. Making Vocational Choices: A Theory of Vocational Personalities and Work Environments; Psychological Assessment Resources: Odessa, FL, USA, 1997.

60. Ackerman, P.L.; Heggestad, E.D. Intelligence, personality, and interests: Evidence for overlapping traits. Psychol. Bull. 1997, 121, 219-245.

61. Ackerman, P.L.; Rolfhus, E.L. The locus of adult intelligence: Knowledge, abilities, and nonability traits. Psychol. Aging 1999, 14, 314-330.

62. Raphals, L. Knowing Words: Wisdom and Cunning in the Classical Traditions of China and Greece; Cornell University Press: Ithaca, NY, USA, 1992.

63. Sternberg, R.J. Beyond IQ: A Triarchic Theory of Human Intelligence; Cambridge University Press: New York, NY, USA, 1985.

64. Dewey, J. Moral Principles in Education; Houghton Mifflin: Boston, MA, USA, 1909.

65. Thorndike, E.L. Intelligence and its uses. Harpers Mag. 1920, 40, 227-235.

66. Hunt, T. The measurement of social intelligence. J. Appl. Psychol. 1928, 12, 317-334.

67. Thorndike, R.L.; Stein, S. An evaluation of the attempts to measure social intelligence. Psychol. Bull. 1937, 34, 275-285.

68. Thorndike, R.L. Factor analysis of social and abstract intelligence. J. Educ. Psychol. 1936, 27, 231-233.

69. Matthews, G.; Emo, A.K.; Roberts, R.D.; Zeidner, M. What is this thing called emotional intelligence? In A Critique of Emotional Intelligence: What Are the Problems and How Can They Be Fixed; Murphy, K.R., Ed.; Lawrence Erlbaum: Mahwah, NJ, USA, 2006; pp. 3-36.

70. Landy, F.J. The long, frustrating, and fruitless search for social intelligence: A cautionary tale. In A Critique of Emotional Intelligence: What Are the Problems and How Can They Be Fixed?; Murphy, K.R., Ed.; Lawrence Erlbaum: Mahwah, NJ, USA, 2006; pp. 81-124.

71. Walker, R.E.; Foley, J.M. Social intelligence: Its history and measurement. Psychol. Rep. 1973, 33, 839-864.

72. Guilford, J.P.; Hoepfner, R. The Analysis of Intelligence; McGraw-Hill: New York, NY, USA, 1971.

73. Cronbach, L.J. Essentials of Psychological Assessment, 2nd ed.; Harper \& Row: New York, NY, USA, 1960.

74. Cronbach, L.J. Essentials of Psychological Assessment, 3rd ed.; Harper \& Row: New York, NY, USA, 1970.

75. O'Sullivan, M.; Guilford, J. Six factors of behavioral cognition: Understanding other people. J. Educ. Meas. 1975, 12, 255-271.

76. Weis, S.; Süß, H.M. Reviving the search for social intelligence-A multitrait-multimethod study of its structure and construct validity. Personal. Individ. Differ. 2007, 42, 3-14.

77. Kihlstrom, J.F.; Cantor, N. Social intelligence. In The Cambridge Handbook Of Intelligence; Sternberg, R.J., Kaufman, S.B., Eds.; Cambridge University Press: New York, NY, USA, 2011; pp. 564-581.

78. Sternberg, R.J.; Smith, C. Social intelligence and decoding skills in nonverbal communication. Soc. Cogn. 1985, 3, 168-192.

79. Matthews, G.; Zeidner, M.; Roberts, R. Emotional intelligence: An elusive ability. In Handbook of Understanding and Measuring Intelligence; Wilhelm, O., Engle, R.W., Eds.; Sage: Thousand Oaks, CA, USA, 2005; pp. 79-100. 
80. Salovey, P.; Mayer, J.D. Emotional intelligence. Imagin. Cogn. Personal. 1990, 9, 185-211.

81. MacCann, C.; Joseph, D.L.; Newman, D.A.; Roberts, R.D. Emotional intelligence is a second-stratum factor of intelligence: Evidence from hierarchical and bifactor models. Emotion 2014, 14, 358-374.

82. Roberts, R.D.; Zeidner, M.; Matthews, G. Does emotional intelligence meet traditional standards for an intelligence? Some new data and conclusions. Emotion 2001, 1, 196-231.

83. Davies, M.; Stankov, L.; Roberts, R.D. Emotional intelligence: In search of an elusive construct. J. Personal. Soc. Psychol. 1998, 75, 989-1015.

84. Mayer, J.D.; Panter, A.T.; Caruso, D.R. Does personal intelligence exist? Evidence from a new ability-based measure. J. Personal. Assess. 2012, 94, 124-140.

85. Gardner, H. Frames of Mind; Basic Books: New York, NY, USA, 1983.

86. Gardner, H. Intelligence Reframed: Multiple Intelligences for the 21st Century.; Basic Books: New York, NY, USA, 1999.

87. Sternberg, R.J. Successful Intelligence; Plume: New York, NY, USA, 1997.

88. Sternberg, R.J. The theory of successful intelligence. Rev. Gen. Psychol. 1999, 3, 292.

89. Mayer, J.D.; DiPaolo, M.; Salovey, P. Perceiving affective content in ambiguous visual stimuli: A component of emotional intelligence. J. Personal. Assess. 1990, 54, 772-781.

90. Mayer, J.D.; Caruso, D.R.; Salovey, P. Emotional intelligence meets traditional standards for an intelligence. Intelligence 1999, 27, 267-298.

91. Mayer, J.D.; Roberts, R.D.; Barsade, S.G. Human abilities: Emotional intelligence. Annu. Rev. Psychol. 2008, 59, 507-536.

92. Mayer, J.D.; Salovey, P.; Caruso, D.R. Emotional intelligence: New ability or eclectic traits? Am. Psychol. 2008, 63, 503-517.

93. Matthews, G.; Zeidner, M.; Roberts, R.D. Emotional Intelligence: Science and Myth; MIT Press: Cambridge, MA, USA, 2004.

94. Mayer, J.D. Personal intelligence expressed: A theoretical analysis. Rev. Gen. Psychol. 2009, 13, 46-58.

95. Mayer, J.D. Personal Intelligence: The Power of Personality and How It Shapes Our Lives; Farrar, Straus and Giroux: New York, NY, USA, 2014.

96. Mayer, J.D.; Skimmyhorn, W. Psychological Predictors of Cadet Performance at West Point; The Association for Research in Personality: St. Louis, MO, USA, 2015.

97. Mayer, J.D.; Salovey, P.; Caruso, D.R. Mayer-Salovey-Caruso Emotional Intelligence Test (MSCEIT) User's Manual; Multi-Health Systems: Toronto, ON, Canada, 2002.

98. Legree, P.J.; Psotka, J.; Robbins, J.; Roberts, R.D.; Putka, D.J.; Mullins, H.M. Profile similarity metrics as an alternate framework to score rating-based tests: MSCEIT reanalyses. Intelligence 2014, 47, 159-174.

99. McNemar, Q. Lost: Our intelligence? Why? Am. Psychol. 1964, 19, 871-882.

100. Guttman, L.; Levy, S. Two structural laws for intelligence tests. Intelligence 1991, 15, 79-103.

101. Cronbach, L.J.; Meehl, P.E. Construct validity in psychological tests. Psychol. Bull. 1955, 52, 281-302.

102. Spearman, C.E. The Nature of "Intelligence" and the Principles of Cognition; Macmillan: London, UK, 1923.

103. Baddeley, A. Fractionating the central executive. In Principles of Rontal Lobe Function; Stuss, D., Knight, R., Eds.; Oxford University Press: New York, NY, USA, 2002; pp. 246-260.

104. Gould, S. The Mismeasure of Man; Norton: New York, NY, USA, 1996.

105. MacCann, C.; Roberts, R.D. New Paradigms for Assessing Emotional Intelligence: Theory and Data. Emotion 2008, 8, 540-551.

106. Mayer, J.D.; Salovey, P.; Caruso, D.R. Mayer-Salovey-Caruso Emotional Intelligence Test: Youth Version-Research Edition (MSCEIT-YV); Multi-Health Systems: Toronto, ON, Canada, 2014.

107. Izard, C.; Fine, S.; Schultz, D.; Mostow, A.; Ackerman, B.; Youngstrom, E. Emotion knowledge as a predictor of social behavior and academic competence in children at risk. Psychol. Sci. 2001, 12, 18-23.

108. Lortie, B. Personal Intelligence at Work. Unpublished Senior Honors Thesis, 2015.

109. Moore, M. Personal Intelligence in the Workplace and Relationships. Unpublished Senior Honors Thesis, 2013.

110. Liu, O.L.; Bridgeman, B.; Adler, R.M. Measuring learning outcomes in higher education motivation matters. Educ. Res. 2012, 41, 352-362.

111. Duckworth, A.L.; Quinn, P.D.; Lynam, D.R.; Loeber, R.; Stouthamer-Loeber, M. Role of test motivation in intelligence testing. Proc. Natl. Acad. Sci. USA 2011, 108, 7716-7720. 
112. Bar-On, R. Bar-On Emotional Quotient Inventory: Technical Manual; Multi-Health Systems: Toronto, ON, Canada, 1997.

113. MacCann, C.; Matthews, G.; Zeidner, M.; Roberts, R.D. Psychological assessment of emotional intelligence: A review of self-report and performance-based testing. Int. J. Organ. Anal. 2003, 11, 247-274.

114. Joseph, D.L.; Jin, J.; Newman, D.A.; O'Boyle, E.H. Why does self-reported emotional intelligence predict job performance? A meta-analytic investigation of mixed EI. J. Appl. Psychol. 2014, 100, 298-342.

115. De Raad, B. The trait-coverage of emotional intelligence. Personal. Individ. Differ. 2005, 38, 673-687.

116. Allen, V.D.; Weissman, A.; Hellwig, S.; MacCann, C.; Roberts, R.D. Development of the Situational Test of Emotional Understanding-Brief (STEU-B) using item response theory. Personal. Individ. Differ. 2014, 65, 3-7.

117. Mayer, J.D.; Salovey, P.; Caruso, D.R.; Sitarenios, G. Emotional intelligence as a standard intelligence. Emotion 2001, 1, 232-242.

118. Campbell, D.T.; Fiske, D.W. Convergent and discriminant validation by the multitrait-multimethod matrix. Psychol. Bull. 1959, 56, 81-105.

119. Marsh, H.W.; Hau, K.T.; Balla, J.R.; Grayson, D. Is more ever too much? The number of indicators per factor in confirmatory factor analysis. Multivar. Behav. Res. 1998, 33, 181-220.

120. Hogarty, K.Y.; Hines, C.V.; Kromrey, J.D.; Ferron, J.M.; Mumford, K.R. The quality of factor solutions in exploratory factor analysis: The influence of sample size, communality, and overdetermination. Educ. Psychol. Meas. 2005, 65, 202-226.

121. Bollen, K.A.; Bauldry, S. Three Cs in measurement models: Causal indicators, composite indicators, and covariates. Psychol. Methods 2011, 16, 265-284.

122. Cronbach, L.J. Assessment of individual differences. Annu. Rev. Psychol. 1956, 7, 173-196.

123. Brackett, M.A.; Mayer, J.D. Convergent, discriminant, and incremental validity of competing measures of emotional intelligence. Personali. Soci. Psychol. Bull. 2003, 29, 1147-1158.

124. Salovey, P.; Mayer, J.D.; Caruso, D.; Lopes, P.N. Measuring emotional intelligence as a set of abilities with the Mayer-Salovey-Caruso Emotional Intelligence Test. In Positive Psychological Assessment: A Handbook of Models and Measures; Lopez, S.J., Snyder, C.R., Eds.; American Psychological Association: Washington, DC, USA, 2003; pp. 251-265.

125. Mayer, J.D.; Salovey, P.; Caruso, D.R.; Sitarenios, G. Measuring emotional intelligence with the MSCEIT V2.0. Emotion 2003, 3, 97-105.

126. Cattell, R.B. The sciEntific Use of Factor Analysis in Behavioral and Life Sciences; Plenum Press: New York, NY, USA, 1978.

127. Outtz, J.L.; Newman, D.A. A theory of adverse impact. In Adverse Impact: Implications for Organizational Staffing and High Stakes Selection; Outtz, J.L., Ed.; Routledge/Taylor \& Francis Group: New York, NY, USA, 2010; pp. 53-94.

128. Wee, S.; Newman, D.A.; Joseph, D.L. More than $g$ : Selection quality and adverse impact implications of considering second-stratum cognitive abilities. J. Appl. Psychol. 2014, 99, 547-563.

129. Dunbar, R.I. The social brain hypothesis and its implications for social evolution. Ann. Hum. Biol. 2009, $36,562-572$.

130. Buss, D.M. Human Nature and Individual Differences. In Handbook of Personality Psychology: Theory and Research, 3rd ed.; Pervin, L.A., Ed.; Guilford Press: New York, NY, USA, 2008; pp. 29-60.

131. Operskalski, J.T.; Paul, E.J.; Colom, R.; Barbey, A.K.; Grafman, J. Lesion mapping the four-factor structure of emotional intelligence. Front. Hum. Neurosci. 2015, 9, 1-11.

132. Krueger, F.; Barbey, A.K.; McCabe, K.; Strenziok, M.; Zamboni, G.; Solomon, J.; Raymont, V.; Grafman, J. The neural bases of key competencies of emotional intelligence. Proc. Natl. Acad. Sci. USA 2009, 106, $22486-22491$.

133. Barbey, A.K.; Colom, R.; Grafman, J. Distributed neural system for emotional intelligence revealed by lesion mapping. Soc. Cogn. Affect. Neurosci. 2014, 9, 265-272.

134. Rozencwajg, P.; Corroyer, D. Strategy development in a block design task. Intelligence 2002, 30, 1-25.

135. Asparouhov, T.; Muthén, B. Exploratory structural equation modeling. Struct. Equ. Model. A Multidiscip. J. 2009, 16, 397-438.

136. Palmer, B.R.; Gignac, G.; Manocha, R.; Stough, C. A psychometric evaluation of the Mayer-Salovey-Caruso Emotional Intelligence Test Version 2.0. Intelligence 2005, 33, 285-305. 
137. Kane, M.J.; Hambrick, D.Z.; Tuholski, S.W.; Wilhelm, O.; Payne, T.W.; Engle, R.W. The generality of working memory capacity: A latent-variable approach to verbal and visuospatial memory span and reasoning. J. Exp. Psychol. Gen. 2004, 133, 189-217.

138. Borsboom, D. Psychometric perspectives on diagnostic systems. J. Clin. Psychol. 2008, 64, 1089-1108.

139. Clint, E.K.; Sober, E.; Garland Jr, T.; Rhodes, J.S. Male superiority in spatial navigation: Adaptation or side effect? Q. Revi. Biol. 2012, 87, 289-313.

140. Hooven, C.K.; Chabris, C.F.; Ellison, P.T.; Kosslyn, S.M. The relationship of male testosterone to components of mental rotation. Neuropsychologia 2004, 42, 782-790.

141. Bartholomew, D.J. Measuring Intelligence: Facts and Fallacies; Cambridge University Press: New York, NY, USA, 2004.

142. Spearman, C.E. The factor theory and its troubles. V. Adequacy of proof. J. Educ. Psychol. 1934, 25, 310-319.

143. Bock, G.; Goode, J.A.; Webb, K. The Nature of Intelligence; Novartis Foundation: London, UK, 2000.

144. Van der Maas, H.L.J.; Dolan, C.V.; Grasman, R.P.P.P.; Wicherts, J.M.; Huizenga, H.M.; Raijmakers, M.E. A dynamical model of general intelligence: The positive manifold of intelligence by mutualism. Psychol. Rev. 2006, 113, 842-861.

145. Joseph, D.L.; Newman, D.A. Emotional intelligence: An integrative meta-analysis and cascading model. J. Appl. Psychol. 2010, 95, 54-78.

(C) 2016 by the authors; licensee MDPI, Basel, Switzerland. This article is an open access article distributed under the terms and conditions of the Creative Commons by Attribution (CC-BY) license (http:/ / creativecommons.org/licenses/by/4.0/). 